\title{
SISTEM PENDUKUNG KEPUTUSAN PENERIMAAN SISWA BARU DI SMK NEGERI 1 TAPUNG HULU MENGGUNAKAN METODE SIMPLE MULTI ATTRIBUT RATING TECHNIQUE (SMART)
}

\author{
Yuda Irawan ${ }^{1)}$, Refni Wahyuni ${ }^{2}$ \\ ${ }^{1}$ Sistem Informasi, ${ }^{2}$ Teknik Informatika, ${ }^{1,2}$ STMIK Hang Tuah Pekanbaru \\ Email : ${ }^{1}$ yudairawan89@gmail.com, ${ }^{2}$ refniabid@gmail.com
}

\begin{abstract}
State Vocational School (SMK) 1 Tapung Hulu is an educational institution under the auspices of the Kampar District Education Office and is the only State Vocational School in Tapung Hulu District. The activity of accepting new students at State Vocational School 1 Tapung Hulu still uses a manual system where participants fill out the registration form on the form provided by the school, then the participant's data is reprocessed by the committee using Microsoft Excel. The use of Microsoft Excel as an application used for the selection process is quite effective because the selection process is only guided by one criterion, namely the National Examination (UN) value and this process requires considerable time. In order for an effective selection process the new student selection committee will involve several criteria that are used as guidelines for the selection process of new students, including the National Examination (UN), School Final Examination (UAS), and Academic Test scores so that a solution is needed. decision support system for multicriteria. The Simple Multi Attribute Rating Technique method or commonly abbreviated as SMART is a method in multi attribute decision making. This multi-attribute decision making technique is used to support decision makers in choosing several alternatives. Every decision maker must have an alternative that is in accordance with the objectives formulated. Decision support system built is very helpful to speed up data processing in decision making to determine new prospective students who are feasible and not eligible to be accepted. Decision support systems using the SMART method built are very helpful to speed up data processing in decision making to determine new prospective students who are feasible and not eligible to be accepted.
\end{abstract}

Keywords: Decision Support System, SPK, Simple Multi Attribute Rating Technique

\begin{abstract}
Abstrak
Sekolah Menengah Kejuruan (SMK) Negeri 1 Tapung Hulu adalah instansi pendidikan di bawah naungan Dinas Pendidikan Kabupaten Kampar dan merupakan satu-satunya SMK Negeri yang ada di Kecamatan Tapung Hulu. Kegiatan penerimaan siswa baru di SMK Negeri 1 Tapung Hulu masih menggunakan sistem manual yaitu peserta mengisi formulir pendaftaran pada form yang telah disediakan oleh pihak sekolah, kemudian data-data peserta tersebut diolah kembali oleh panitia menggunakan microsoft excel. Penggunaan microsoft excel sebagai aplikasi yang digunakan untuk proses seleksi cukup efektif dikarenakan proses seleksi hanya berpedoman pada satu kriteria yaitu nilai Ujian Nasional (UN) dan proses ini membutuhkan waktu yang cukup lama. Agar proses seleksi lebih efektif panitia pemilihan siswa baru akan melibatkan beberapa kriteria yang digunakan sebagai pedoman untuk proses seleksi calon siswa baru, diantaranya nilai Ujian Nasional (UN), nilai Ujian Akhir Sekolah (UAS), serta nilai Tes Akademik sehingga dalam proses penyelesaiannya diperlukan sebuah sistem pendukung keputusan untuk multikriteria. Metode Simple Multi Attribute Rating Technique atau yang biasa disingkat SMART merupakan metode dalam pengambilan keputusan multi atribut. Teknik pengambilan keputusan multi atribut ini digunakan untuk mendukung pembuat keputusan dalam memilih beberapa alternatif. Setiap pembuat keputusan harus memiliki sebuah alternatif yang sesuai dengan tujuan yang dirumuskan. Sistem pendukung keputusan yang dibangun sangat membantu untuk mempercepat pengolahan data dalam pengambilan keputusan untuk menentukan calon siswa baru yang layak dan tidak layak untuk diterima. Sistem pendukung keputusan menggunakan metode SMART yang dibangun sangat membantu untuk mempercepat pengolahan data dalam pengambilan keputusan untuk menentukan calon siswa baru yang layak dan tidak layak untuk diterima.
\end{abstract}

Kata Kunci: Sistem Pendukung Keputusan, SPK, Simple Multi Atribute Rating Technique, SMART 


\section{PENDAHULUAN}

Penerimaan Siswa Baru adalah kegiatan rutin yang dilaksanakan di seluruh sekolah menjelang tahun ajaran baru. SMK Negeri 1 Tapung Hulu adalah instansi pendidikan di bawah naungan Dinas Pendidikan Kabupaten Kampar dan merupakan satu-satunya SMK Negeri yang ada di Kecamatan Tapung Hulu sebagai tujuan bagi siswa yang lulus dari Sekolah Menengah Pertama (SMP) untuk meneruskan pandidikannya di tingkat selanjutnya. Kegiatan penerimaan siswa baru di SMK Negeri 1 Tapung Hulu masih menggunakan sistem manual yaitu peserta mengisi formulir pendaftaran pada form yang telah disediakan oleh pihak sekolah, kemudian data-data peserta tersebut diolah kembali oleh panitia menggunakan microsoft excel. Penggunaan microsoft excel sebagai aplikasi yang digunakan untuk proses seleksi cukup efektif dikarenakan proses seleksi hanya berpedoman pada satu kriteria yaitu nilai Ujian Nasional (UN), meskipun proses ini membutuhkan waktu yang cukup lama. Agar proses seleksi lebih efektif panitia pemilihan siswa baru akan melibatkan beberapa kriteria yang digunakan sebagai pedoman untuk proses seleksi calon siswa baru, diantaranya nilai Ujian Nasional (UN), nilai Ujian Akhir Sekolah (UAS), serta nilai Tes Akademik sehingga dalam proses penyelesaiannya diperlukan sebuah sistem pendukung keputusan untuk multikriteria. Adapun metode sistem pendukung keputusan diantaranya dengan menggunakan metode Simple Multi Atribute Rating Technique (SMART). Metode Simple Multi Attribute Rating Technique atau yang biasa disingkat SMART merupakan metode dalam pengambilan keputusan multi atribut. Teknik pengambilan keputusan multi atribut ini digunakan untuk mendukung pembuat keputusan dalam memilih beberapa alternatif. Setiap pembuat keputusan harus memiliki sebuah alternatif yang sesuai dengan tujuan yang dirumuskan.

Sistem penunjang keputusan sebagai sistem yang digunakan untuk mendukung dan membantu pihak manajemen melakukan pengambilan keputusan pada kondisi semi terstruktur dan tidak terstruktur. Pada dasarnya konsep DSS hanyalah sebatas pada kegiatan membantu para manajer melakukan penilaian serta menggantikan posisi dan peran manajer (Turban, 2005).
SMART menggunakan linear additive model untuk meramal nilai setiap alternatif. SMART merupakan metode pengambilan keputusan yang fleksibel. SMART lebih banyak digunakan karena kesederhanaanya dalam merespon kebutuhan pembuat keputusan dan caranya menganalisa respon. Analisa yang terlibat adalah transparan sehingga metode ini memberikan pemahaman masalah yang tinggi dan dapat diterima oleh pembuat keputusan (Ardian NS, 2013).

Penelitian dengan menerapkan metode Simple Multi Attribute Rating Technique (SMART) pernah dilakukan oleh Jupri pada tahun 2014 dengan judul Sistem Pendukung Keputusan Pemilihan Bahan Obat Alternatif menggunakan metode Simple Multi Attribute Rating Technique, hasil penelitian ini membantu dan mempermudah pengguna mendapatkan informasi tentang bahan obat tersebut dengan tepat dan dapat menentukan pemilihan yang tepat terhadap bahan obat.

Penelitian dilakukan oleh Tisa Magrisa (2018) dengan judul implementasi metode SMART pada sistem pendukung keputusan pemeilihan kegiatan ekstrakurikuler untuk siswa SMA. Metode SMART yang digunakan pada pembuatan sistem pendukung keputusan kegiatan ekstrakurikuler ini telah mampu menjawab masalah yang ada dengan adanya respon dari responden sebesar $83,415 \%$ sangat setuju bahwa sistem ini mampu membantu siswa dalam memilih kegiatan ekstrakurikuler.

Penelitian dilakukan oleh Suryanto (2015) dengan judul Sistem Pendukung Keputusan Pemilihan Karyawan Teladan dengan Metode SMART. Berdasarkan penelitian yang dilakukan dengan penyebaran kuesioner terhadap Admin didapatkan hasil persentase sistem berada pada kisaran angka $83.57 \%$ dan Manager didapatkan hasil persentase sistem berada pada kisaran angka 83\%. Sehingga dapat memberikan rekomendasi yang tepat dan sesuai serta dapat membantu dalam penilaian pemilihan karyawan teladan.

\section{METODE PENILITIAN}

\subsection{Tahap pengumpulan data}

Cara pengumpulan data yang digunakan dalam penelitian ini adalah sebagai berikut : 


\subsubsection{Pengumpulan Data Primer}

Data primer adalah data yang diperoleh secara langsung dari objek penelitian, Meliputi :

a. Observasi

Observasi adalah metode pengumpulan data yang kompleks karena melibatkan berbagai faktor dalam pelaksanaannya. Metode pengumpulan data observasi tidak hanya mengukur sikap dari responden, namun juga dapat digunakan untuk merekam berbagai fenomena yang terjadi. Teknik pengumpulan data observasi cocok digunakan untuk penelitian yang bertujuan untuk mempelajari perilaku manusia, proses kerja, dan gejalagejala alam. Metode ini juga tepat dilakukan pada responden yang kuantitasnya tidak terlalu besar.

\section{b. Wawancara}

Wawancara adalah teknik pengumpulan data yang dilakukan melalui tatap muka dan Tanya jawab langsung Antara peneliti dan narasumber. Seiring perkembangan teknologi, metode wawancara dapat pula dilakukan melalui media-media tertentu, misalnya telepon, email, atau skype.

\subsubsection{Pengumpulan Data Skunder}

Adalah data yang diambil dari bukubuku, dokumentasi, dan literatur-literatur. Meliputi :

a. Studi Kepustakaan

Pengumpulan data dari buku-buku atau literatur yang sesuai dengan tema permasalahan, misalnya buku atau literature tentang manajemen pengelolaan data.

\section{b. Studi Dokumentasi}

Pengumpulan data dari literatur-literatur dan dokumentasi dari Internet, dan sumber informasi lain, misalnya alamat url dari jurnal yang ada di internet, definisi analisis kebutuhan berdasarkan penelitian.

\subsubsection{Metode Pengembangan Perangkat Lunak}

Proses Pengembangan Perangkat Lunak (Software Development Process) adalah suatu penerapan struktur pada pengembangan suatu Perangkat Lunak (Software), yang bertujuan untuk mengembangkan sistem dan memberikan panduan untuk menyukseskan proyek pengembangan sistem melalui tahapan-tahapan tertentu.

Model Sekuensial Linier atau Waterfall Development Model. Model Sekuensial Linier atau sering disebut Model Pengembangan Air Terjun, merupakan paradigma model pengembangan perangkat lunak paling tua, dan paling banyak dipakai. Model ini mengusulkan sebuah pendekatan perkembangan perangkat lunak yang sistematik dan sekunsial yang dimulai pada tingkat dan kemajuan sistem pada seluruh tahapan analisis, desain, kode, pengujian, dan penerapan program (Abdul Kadir, 2003).

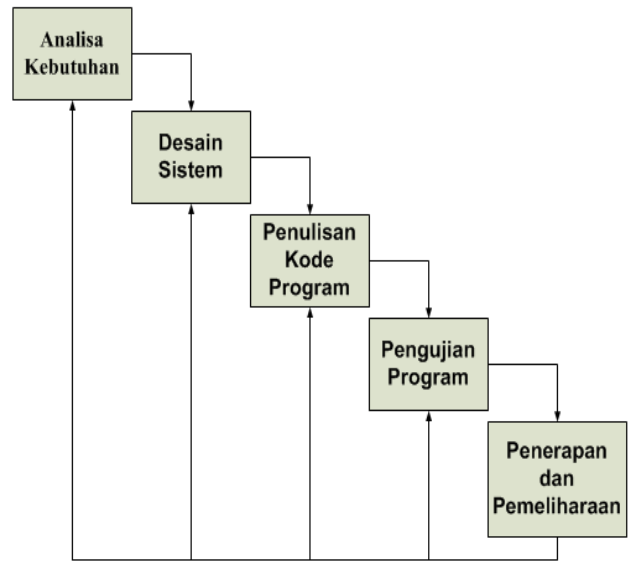

Gambar 1. Waterfall Development Model

Berikut Merupakan Tahapan - tahapan Pengembangan Model Sekuensial Linear / Waterfall Development Model :

\section{Analisis Kebutuhan}

Langkah ini merupakan analisa terhadap kebutuhan sistem. Pengumpulan data dalam tahap ini bisa melakukan sebuah penelitian, wawancara atau studi literatur. Sistem analis akan menggali informasi sebanyak-banyaknya dari user sehingga akan tercipta sebuah sistem komputer yang bisa melakukan tugas-tugas yang diinginkan oleh user tersebut. Tahapan ini akan menghasilkan dokumen user requirment atau bisa dikatakan sebagai data yang berhubungan dengan keinginan user dalam pembuatan sistem. Dokumen ini lah yang akan menjadi acuan sistem analis untuk menerjemahkan ke dalam bahasa pemrograman. 


\section{Desain sistem}

Tahapan dimana dilakukan penuangan pikiran dan perancangan sistem terhadap solusi dari permasalahan yang ada dengan menggunakan perangkat pemodelan sistem seperti unified modeling language (UML), diagram hubungan entitas (entity relationship diagram) serta struktur dan bahasan data.

\section{Penulisan Kode Program}

Penulisan kode program atau coding merupakan penerjemahan design dalam bahasa yang bisa dikenali oleh komputer. Dilakukan oleh programmer yang akan menterjemahkan transaksi yang diminta oleh user. Tahapan ini lah yang merupakan tahapan secara nyata dalam mengerjakan suatu sistem. Dalam artian penggunaan komputer akan dimaksimalkan dalam tahapan ini. Setelah pengkodean selesai maka akan dilakukan testing terhadap sistem yang telah dibuat tadi. Tujuan testing adalah menemukan kesalahan-kesalahan terhadap sistem tersebut dan kemudian bisa diperbaiki.

\section{Pengujian}

Setelah Proses Pengkodean selesai,

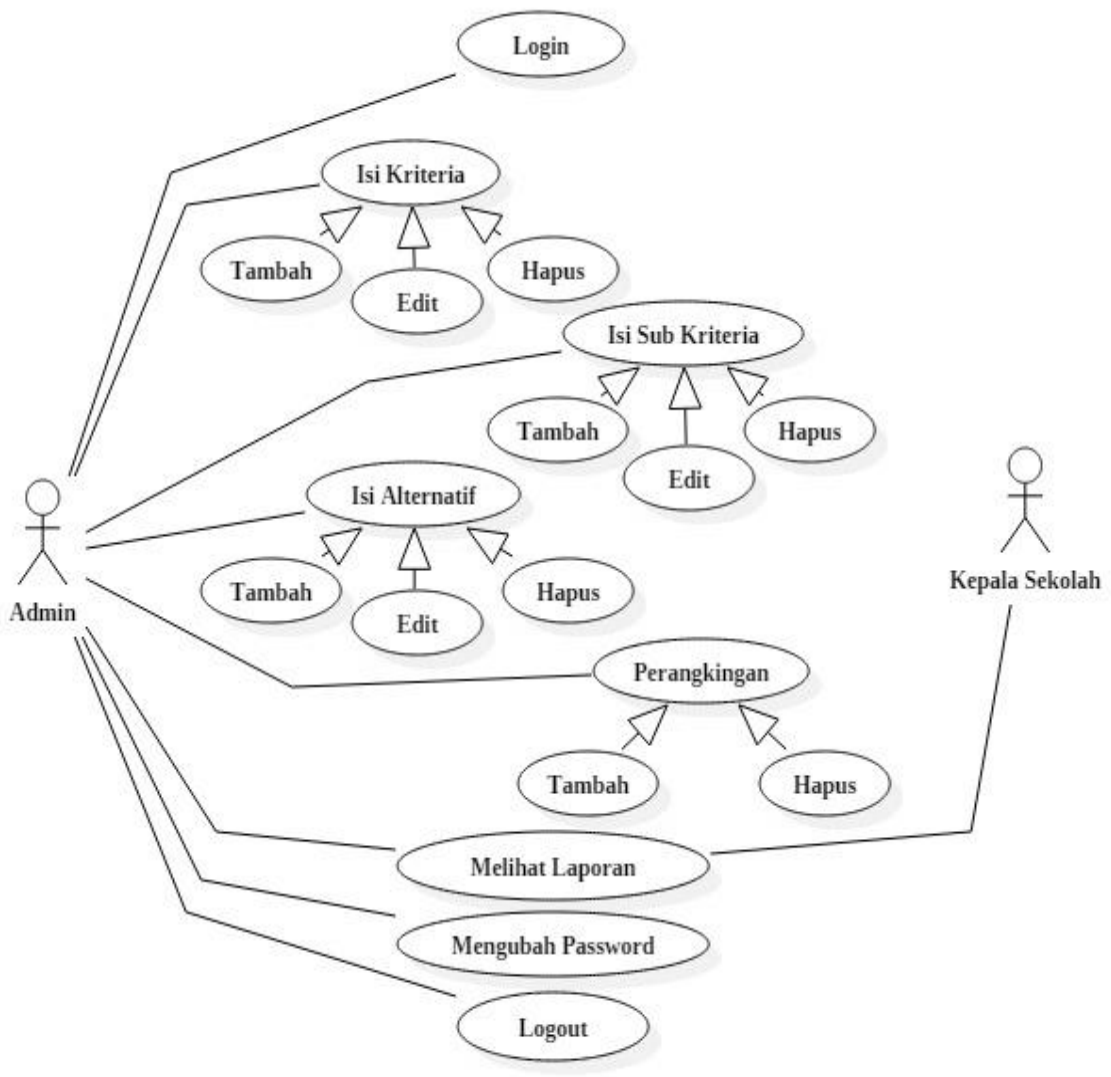

Gambar 2. Diagram Use Case dilanjutkan dengan proses pengujian pada program perangkat lunak, baik Pengujian logika internal, maupun Pengujian eksternal fungsional untuk memeriksa segala kemungkinan terjadinya kesalahan dan memeriksa apakah hasil dari pengembangan tersebut sesuai dengan hasil yang diinginkan.

\section{Penerapan Program dan} Pemeliharaan

Perangkat lunak yang sudah disampaikan kepada pelanggan pasti akan mengalami perubahan. Perubahan tersebut bisa karena mengalami kesalahan karena perangkat lunak harus menyesuaikan dengan lingkungan (periperal atau sistem operasi baru) baru, atau karena pelanggan membutuhkan perkembangan fungsional.

\section{HASIL DAN PEMBAHASAN}

\subsection{Analisa Sistem Yang Diusulkan}

Berikut use case yang terbentuk dari Sistem Pendukung Keputusan Penerimaan Siswa Baru di SMK Negeri 1 Tapung Hulu. 
Diagram class merupakan diagram yang menunjukkan kebutuhan class-class dalam suatu sistem program dimana class-class tersebut mengandung atribut-atribut dan operasi-operasi yang dibutuhkan. Class juga merupakan pembentuk utama dari sistem berorientasi objek karena class menunjukkan kumpulan objek yang memiliki atribut dan operasi yang sama. Class digunakan untuk mengimplementasikan interface. Dalam satu class, terdapat atribut dan operation yang berkaitan dengan class tersebut. Kemudian class-class yang telah didefinisikan satu sama lain melalui relasi yang terjadi antara class-class tersebut.

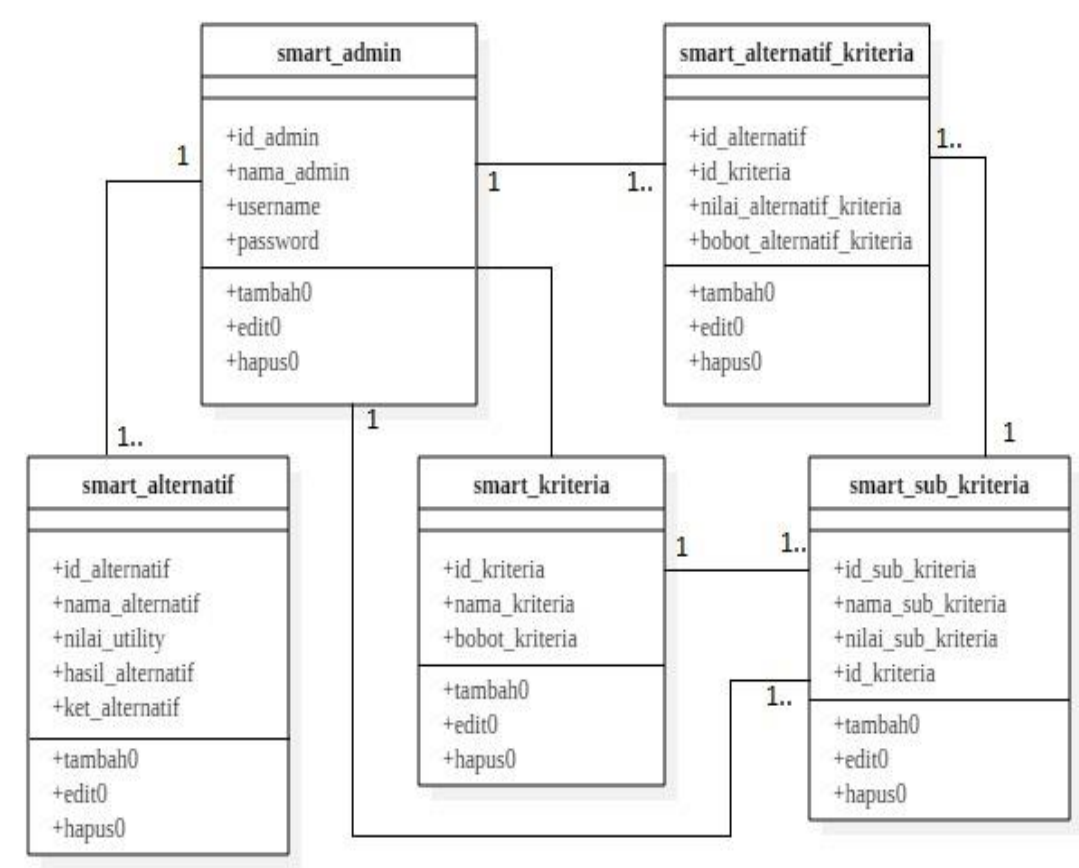

Gambar 3. Class Diagram

\subsection{Proses Pemodelan Metode SMART.}

Urutan dalam penggunaan metode SMART (Goodwin dan Wright, 2004) adalah sebagai berikut :

1. Menentukan banyaknya kriteria digunakan.

2. Menentukan bobot kriteria pada masingmasing kriteria dengan menggunakan interval 1-100 untuk masing-masing kriteria dengan prioritas terpenting.

3. Hitung normalisasi dari setiap kriteria dengan membandingkan nilai bobot kriteria dengan jumlah bobot kriteria.

\subsection{Tampilan Menu Utama Admin}

Pada Menu ini admin dapat mengakses kriteria, sub kriteria, alternatif, perangkingan, laporan, operator, ubah password, dan logout setelah berhasil login kedalam sistem sebagai "Admin". 

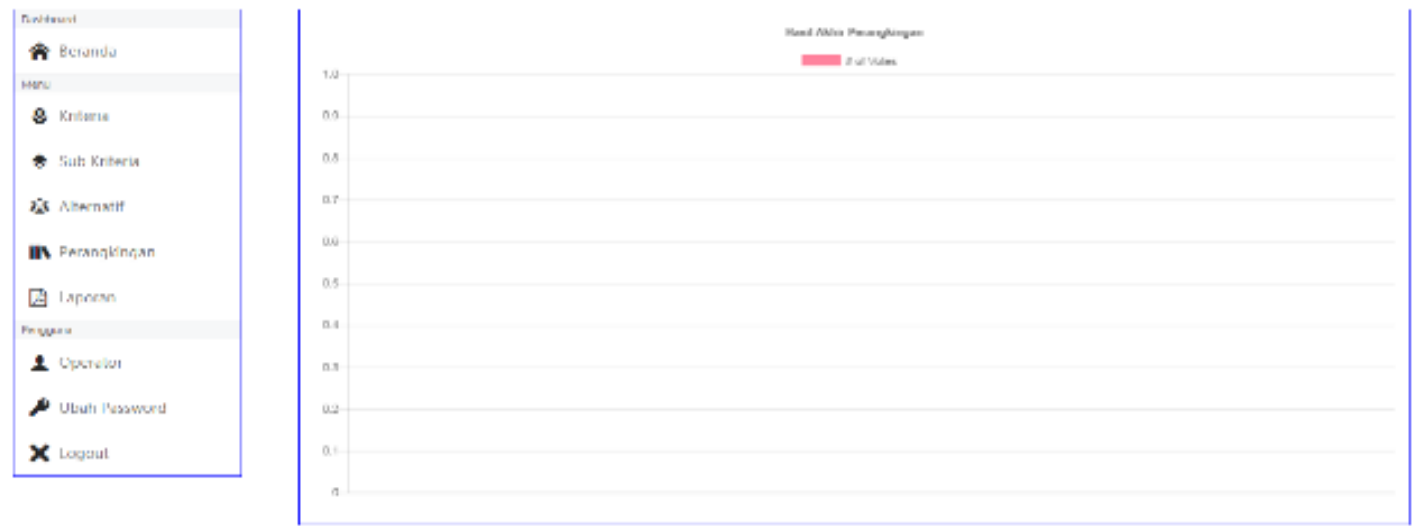

Gambar 4. Tampilan Menu Utama

\subsection{Tampilan Menu Kriteria}

Pada menu kriteria, admin akan menginputkan kriteria-kriteria apa saja yang digunakan dalam proses penyeleksian. Admin juga bisa menghapus dan mengubah data yang telah tersimpan pada menu kriteria.

SPK Metode SMART Kriteria Sub Kriterid Altemauti Perangkingan Laporen
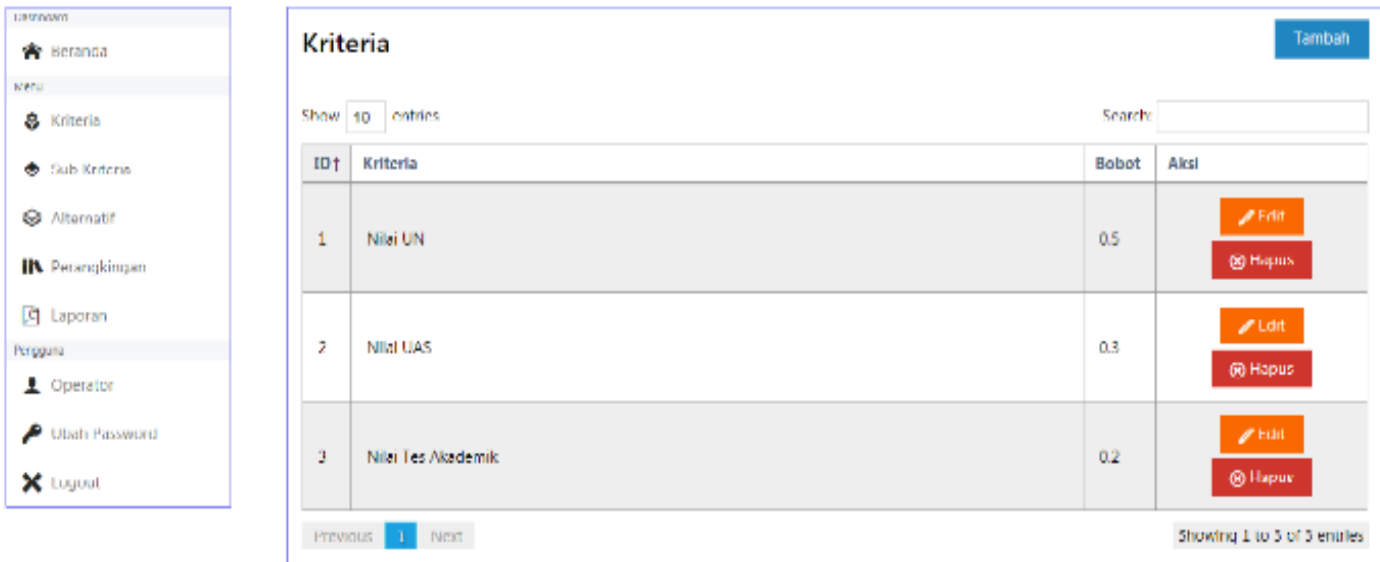

Gambar 5. Tampilan Menu Kriteria

\subsection{Tampilan Menu Laporan}

Pada menu laporan akan ditampilkan laporan hasil perangkingan, pada menu ini juga akan diketahui daftar siswa yang dinyatakan layak dan tidak layak untuk melanjutkan pendidikan di SMK Negeri 1 Tapung Hulu. 


\begin{tabular}{|c|c|c|c|c|c|c|}
\hline No & Nama Calon Siswa Baru & Nilai UN & Nilai UAS & Nilai Tes Akademik & Hasil & Keterangan \\
\hline - & Bubol & 0.5 & 0.3 & 0.2 & - & - \\
\hline 1 & Erwin & 35 & 25.5 & 14 & 74.5 & Layak \\
\hline 2 & M. Abdul Annas & 42.5 & 21 & 14 & 77.5 & Layak \\
\hline 3 & Zulkamain & 35 & 21 & 14 & 70 & layak \\
\hline 4 & Jullandi Prayoga & 35 & 21 & 14 & 10 & Layak \\
\hline 5 & Cornel Arneto Berutu & 35 & 19.5 & 13 & 67.5 & Layak \\
\hline 6 & Danu & 35 & 21 & 13 & 69 & Layak \\
\hline 7 & Doni Alralah Sinaya & 32.5 & 21 & 17 & 70.5 & Layak \\
\hline 8 & Ryan Setiawan & 35 & 21 & 10 & 66 & Layak \\
\hline 9 & Ismail Karim & 42.5 & 25.5 & 13 & 81 & Layak \\
\hline 10 & Snfyan Itrahim Siregnr & 32.5 & 21 & 17 & 70.5 & layak \\
\hline 11 & Sadam Himawan & 25 & 19.5 & 10 & $54: 5$ & IIdak Layak \\
\hline 12 & Rome nanni & 375 & $n$ & 14 & 675 & I auak \\
\hline
\end{tabular}

Gambar 6. Tampilan Menu Laporan

\section{SIMPULAN DAN SARAN}

\subsection{Kesimpulan}

Berdasarkan hasil penelitian dan pembahasan, maka kesimpulan yang dapat diambil dari penelitian ini adalah sebagai berikut :

1. Sistem pendukung keputusan yang dibangun sangat membantu untuk mempercepat pengolahan data dalam pengambilan keputusan untuk menentukan Calon siswa baru yang layak dan tidak layak untuk diterima.

2. Sistem yang dibangun bersifat dinamis terhadap penentuan alternatif, kriteria dan subkriteria. Sehingga, dapat dirubah sesuai dengan kebutuhan pihak SMK Negeri 1 Tapung Hulu dalam menentukan peserta didik yang layak.

3. Metode SMART merupakan metode yang cocok untuk diterapkan dalam pengambilan keputusan dengan berbagi alternatif, khususnya penyeleksian calon siswa baru secara cepat dan tepat.

\subsection{Saran}

Saran-saran yang diberikan penilitian ini adalah:

1. Aplikasi Sistem Pendukung Keputusan ini masih dapat dikembangkan lagi sehingga sistem penyeleksian calon siswa baru dapat dilakukan dengan lebiih baik lagi.

2. Pengembangan aplikasi Sistem Pendukung Keputusan penerimaan calon siswa baru bisa dengan menghubungkan aplikasi pada website sekolah, sehingga pengumuman hasil seleksi dapat diakses pada website SMK Negeri 1 Tapung Hulu.

\section{DAFTAR PUSTAKA}

Turban. 2005. Dessicion Support System And Intellegent System. Yogyakarta : Andi.

Ardian Nurin Nasution, Penerapan Metode Simple Multi Attribute Rating Technique Untuk Penentuan Bintang Nararia Bhayangkara (Studi Kasus : Kepolisian Daerah Riau), Skripsi Universitas Islam Negeri Sultan Syarif Kasim Pekanbaru, 2013

Magrisa Tisa. 2018. Implementasi Metode SMART pada Sistem Pendukung Keputusan Pemilihan Kegiatan Ekstrakurikuler untuk Siswa SMA. Jurnal Ilmiah Ilmu Komputer Vol. 13, No. 1 Hal 49. Informatika Mulawarman.

Suryanto. 2015. Sistem Pendukung Keputusan Pemilihan Karyawan Teladan dengan Metode SMART (Simple Multi Attribute Rating Technique). Jurnal CoreIT Vol 1, No 1.

Goodwin, P., \& Wright, G. 2004.Decision Analysis For Management Judgment 3rd edition. Newyork : John Wiley \& Sons

Jupri. 2014. Sistem Pendukung Keputusan Pemilihan Bahan Obat Alternatif menggunakan metode Simple Multi Attribute Rating Technique. Program Studi Ilmu Komputer Universitas Mulawarman.

Abdul Kadir. 2003. Pengenalan Sistem Informasi. Andi. Yogyakarta. 